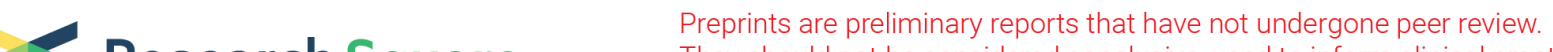 Research Square
They should not be considered conclusive, used to inform clinical practice,
or eferenced by the media as validated information.
}

\section{Streptomyces Grisecoloratus Sp. Nov., a New Bacterium Isolated From Soil in Cotton Fields in Xinjiang, China}

\section{Li Xing}

Key Laboratory of Protection and Utilization of Biological Resources in Basin of Xinjiang Production Construction Corps/College of Life Science,Tarim University,Alar 843300,PR China

\section{Ying-Ying Xia}

Key Laboratory of Protection and Utilization of Biological Resources in Tarim Basin of Xinjiang Production Construction Corps/College of Life Science,Tarim University, Alar 843300, PR China

\section{Qiao-Yan Zhang}

Key Laboratory of Protection and Utilization of Biological Resources in Tarim Basin of Xinjiang Production Construction Corps/College of Life Science, Tarim University, Alar 843300, PR China

\section{Zhan Feng Xia}

Key Laboratory of Protection and Utilization of Biological Resources in Tarim Basin of Xinjiang Production Construction Corps/College of Life Science, Tarim University ,Alar 843300,PR China

\section{Chuan-Xing Wan}

ta li mu da xue: Tarim University

\section{Li Li Zhang}

Key Laboratory of Protection and Utilization of Biological Resources in Tarim Basin of Xinjiang Production Construction Corps/College of Life Science, Tarim University, Alar 843300, PR China Xiao-Xia Luo ( $\nabla$ xxluo425@163.com )

Key Laboratory of Protection and Utilization of Biological Resources in Tarim Basin of Xinjiang Production https://orcid.org/0000-0002-3970-0608

\section{Original Paper}

Keywords: Streptomyces grisecoloratus, Streptomycetaceae, novel species, polyphasic, taxonomy

Posted Date: February 16th, 2021

DOI: https://doi.org/10.21203/rs.3.rs-201561/v1

License: (c) (1) This work is licensed under a Creative Commons Attribution 4.0 International License. Read Full License 


\section{Abstract}

A novel bacterium of the Streptomyces genus, designated TRM S81- ${ }^{\top}$, was isolated from soil in cotton fields of Xinjiang, China. Comparative 16S rRNA gene sequence analysis indicated that strain TRM S81$3^{\top}$ ismost closely related to Streptomyces naganishii $\mathrm{NBRC} 12892^{\top}$ (98.96\% sequence similarity); however, the average nucleotide identity (ANI) between strains TRM S81-3 ${ }^{\top}$ and $S$. naganishii NBRC $12892^{\top}$ is relatively low (86.26\%). Strain TRM S81-3 ${ }^{\top}$ possesses LL-diaminopimelic acid as the diagnostic cell-wall diamino acid, MK-9 $\left(\mathrm{H}_{4}\right), M K-9\left(\mathrm{H}_{6}\right)$, and MK-9 $\left(\mathrm{H}_{10}\right)$ as the major menaquinones, and polar lipids including DPG, $\mathrm{PE}, \mathrm{PC}, \mathrm{PI}, \mathrm{PME}, \mathrm{NPG}$ and $\mathrm{PL}$. The major fatty acids are iso- $\mathrm{C}_{16: 0}$, anteiso- $\mathrm{C}_{15: 0}$, anteiso- $\mathrm{C}_{17: 1} \omega 9 c$, anteiso- $\mathrm{C}_{17: 0}$, iso- $\mathrm{C}_{15: 0}$, and $\mathrm{C}_{14: 0}$. The genomic DNA G+C content is $72.1 \%$. Based on the evidence from this polyphasic study, strain TRM $S 81-3^{\top}$ represents a novel species of Streptomyces, for which the name Streptomyces grisecoloratus is proposed. The type strain is TRM S81-3 ${ }^{\top}$ (=CCTCC AA $2020002^{\top}=$ LMG $31942^{\top}$ ).

\section{Introduction}

The genus Streptomyces, first proposed by Waksman and Henrici (Waksman and Henrici 1943), belongs to the family Streptomycetaceae. At the time of writing, more than 957 species of Streptomyces have been described (Genus: Streptomyces (bacterio.net)). Streptomyces strains are widely distributed and found in a variety of environments, including the desert (Li et al. 2019), sediments (Ay et al. 2018, Hu et al. 2012), insects (Ye et al. 2017), lichens (Saeng-In et al. 2017), the rhizosphere (Piao et al. 2018), and plants (Wang et al. 2018). Members of the genus Streptomyces are Gram-positive, aerobic actinomycetes that have high DNA G + C contents (69-73 mol\%) (Manfio 1995, Anderson and Wellington 2001). These species have diverse metabolic pathways and potential applications in the production of antibiotics, vitamins, enzymes, enzyme inhibitors, and bioactive compounds of importance to the food, agricultural, and pharmaceutical industries (Lazzarini et al. 2000, McCarthy and Williams 1992). In this study, we isolated an actinomycete strain, designated TRM $S 81-3^{T}$. We performed a polyphasic taxonomic analysis of this strain and propose that it represents a novel species of the genus Streptomyces.

\section{Materials And Methods}

\section{Strain isolation and culturing}

Strain TRM S81-3 ${ }^{\top}$ was isolated from a soil sample collected from cotton fields in Xinjiang in northwest China $\left(40^{\circ} 22^{\prime} \mathrm{N} 80^{\circ} 30^{\prime} \mathrm{E}\right)$. The sample was isolated on GJ medium using a 10 -fold dilution series method with incubation at $28^{\circ} \mathrm{C}$. The composition of GJ medium was (per liter of distilled water): $2 \mathrm{~g}$ arginine, $12.5 \mathrm{~g}$ glycerin, $0.01 \mathrm{~g} \mathrm{FeSO}_{4} \cdot 7 \mathrm{H}_{2} \mathrm{O}, 2 \mathrm{~g} \mathrm{~K}_{2} \mathrm{HPO}_{4} \cdot 3 \mathrm{H}_{2} \mathrm{O}$, and $16 \mathrm{~g}$ agar. The strain was purified on Gause's medium at $28^{\circ} \mathrm{C}$. The strain was stored in $20 \%$ glycerol for short-term storage and lyophilized in $20 \%$ skim milk powder for long-term storage. 


\section{Morphological, culture, physiological, and biochemical characteristics}

To determine the culture characteristics, strain TRM S81-3 ${ }^{\top}$ was cultured on a series of ISP media (ISP1, ISP2, ISP3, ISP4, ISP5, ISP6, and ISP7) (Shirling and Gottlieb 1966), Gause's synthetic medium (Atlas 1993), Czapek's agar, potato dextrose agar, and nutrient agar medium (Waksman 1967). The medium was adjusted to $\mathrm{pH}$ 7.0-7.5. The organism was grown and maintained on Gause's synthetic medium. Cell morphological observations of spores and mycelia were conducted by SEM (JSM-6360; JEOL, Ltd., Tokyo, Japan) of cultures on Gause's synthetic plates incubated at $28^{\circ} \mathrm{C}$ for 1 week. Carbon-source utilization tests were performed according to the method described by Shirling et al. (1966) and using the basal medium recommended by Pridham and Gottlieb (1968). The ability of strain TRM S81-3 ${ }^{\top}$ to grow from $10^{\circ} \mathrm{C}-55^{\circ} \mathrm{C}\left(10^{\circ} \mathrm{C}, 12^{\circ} \mathrm{C}, 15^{\circ} \mathrm{C}, 20^{\circ} \mathrm{C}, 25^{\circ} \mathrm{C}, 28^{\circ} \mathrm{C}, 30^{\circ} \mathrm{C}, 37^{\circ} \mathrm{C}, 40^{\circ} \mathrm{C}, 45^{\circ} \mathrm{C}, 50^{\circ} \mathrm{C}\right.$, and $\left.55^{\circ} \mathrm{C}\right)$ and $\mathrm{pH} 4-$ $12(\mathrm{pH} 4,5,6,7,8,9,10,11$, and 12$)$ and to tolerate concentrations of $0 \%-10 \%(0 \%, 1 \%, 2 \%, 3 \%, 4 \%, 5 \%$, $6 \%, 7 \%, 8 \%, 9 \%$, and $10 \%, \mathrm{w} / \mathrm{v}) \mathrm{NaCl}$ was tested using Gause's agar as the basal medium. The production of peroxidase, urease, esterase, and catalase was tested using the method described by Gerhardt et al. (1994) . The use of a sole carbon source $(0.5 \%, \mathrm{w} / \mathrm{v})$, cellulose decomposition, starch hydrolysis, liquefaction of gelatin, milk peptonization and solidification, nitrate reduction, and production of $\mathrm{H}_{2} \mathrm{~S}$ (Gordon 1974, Yokota et al. 1993) were studied.

\section{Chemotaxonomy}

Biomass used for studies was obtained by culturation in liquid Gause's medium for 7 days with shaking at $28^{\circ} \mathrm{C}$. Standard procedures were used to determine the type of amino acids and sugars in cell-wall hydrolysates (Hasegawa et al. 1983). Menaquinones were extracted using the method of Collins (1985) and analyzed by HPLC (Groth et al. 1997). Polar lipids were extracted, examined by two-dimensional TLC, and identified by using the procedures of Minnikin et al. (1984). Cellular fatty acid composition was determined as described by Kampfer et al. (1996) using the Sherlock Microbial Identification System (Version 6.1; MIDI database: RTSBA6; MIDI Inc., Newark, DE, USA).

\section{Genome sequencing and phylogenetic analysis}

Genomic DNA of strain TRM S81-3 $3^{\top}$ was extracted from cells grown on Gause's liquid medium for a week at $28^{\circ} \mathrm{C}$ and used as a template for subsequent PCR amplification. Amplification and sequencing of the 16S rRNA gene were performed as described by Kimc et al. (2000). Alignments of multiple 16S rRNA sequences of closely related members of the genus Streptomyces and sequence similarity calculations were carried out using the EzTaxon-e server (Yoon et al. 2017.). Multi-locus sequence analysis (MLSA) was carried out using the housekeeping genes used in previous Streptomyces analyses: atpD (ATP synthase $\mathrm{F} 1$, beta subunit), gyrB (DNA gyrase B subunit), recA (recombinase A), rpoB (RNA polymerase, beta subunit), and $\operatorname{trp} B$ (tryptophan synthase, beta subunit). Sequences of strain TRM S81-3 ${ }^{\top}$ were obtained through genome sequencing (GenBank number: JACVQF000000000), and the position of these genes in the genome are 01437, 02082, 01122, 03486, and 01287, respectively. The sequences for these loci in related strains were obtained from the ARS Microbial Genome Sequence Database server 
(http://199.133.98.43). For each strain, these five loci were concatenated head-to-tail in-frame as follows: atpD, gyrB, recA, rpoB, and trpB. Phylogenetic trees for $16 \mathrm{~S}$ rRNA and the concatenated multi-locus sequences were constructed using the neighbor-joining (Saitou and Nei 1987), maximum-likelihood (Felsenstein 1981), and maximum-parsimony (Mount 2008) algorithms in the MEGA X program (Kumar et al. 2018). For the neighbor-joining method, evolutionary distance matrices were calculated using the Kimura two-parameter model (Kimura 1980) with SeaView, Version 4.2 (Gouy et al. 2010). For maximumlikelihood analysis, the best model $(\mathrm{JTT}+\mathrm{l}+\mathrm{G})$ was chosen via the program ProtTest 3 (Darriba et al. 2011). The topologies of the resultant phylogenetic trees were evaluated by bootstrap resampling with 1000 replicates (Felsenstein 1992). Because the topologies of these trees were similar, only the neighborjoining tree is shown (Fig. 2). To determine genomic relatedness, the average nucleotide identity (ANI) was determined using OrthoANI with default parameters (https://www.ezbiocloud.net/tools/ani) (Yoon et al. 2017).

\section{Results And Discussion}

After one week of culture, strain TRM S81-3 ${ }^{\top}$ exhibited branched substrate hyphae and aerial hyphae. Under the electron microscope, the spore surface was spiny, and the spores were short and rod-shaped with dimensions of approximately $0.5 \mu \mathrm{m} \times 1.5 \mu \mathrm{m}$ (Fig. 1). Culture characteristics of strain TRM S81-3 ${ }^{\top}$ were determined on ISP series media (ISP1, ISP2, ISP3, ISP4, ISP5, ISP6, and ISP7), Gause's synthetic medium, Czapek's agar, potato dextrose agar, and nutrient agar medium. Poor growth was observed on ISP5 medium and Czapek's agar, and aerial hyphae did not form on ISP6 medium. The growth on other media was vigorous. No diffusible pigments or melanin were observed on any of the media tested. The growth ranges of TRM S81-3 $3^{\top}$ were temperatures $10^{\circ} \mathrm{C}-50^{\circ} \mathrm{C}$ and $\mathrm{pH} 4.0-12.0$, with optimal growth at $28^{\circ} \mathrm{C}$ and $\mathrm{pH} 5.0-10.0$. The $\mathrm{NaCl}$ concentration range for growth was $0-10 \%$, with optimal growth at $0 \%$. Other physiological characteristics of strain TRM S81-3 ${ }^{\top}$ are given in the species descriptions (Table 1). The strain was positive for nitrate reduction, catalase production, milk coagulation and peptization, starch hydrolysis, cellulose hydrolysis, and urease production but negative for gelatin hydrolysis, oxidase production, melanin production, and $\mathrm{H}_{2} \mathrm{~S}$ production. The strain could degrade Tweens $20,40,60$, and 80.

Strain TRM S81-3 $3^{\top}$ contained LL-diaminopimelic acid as its cell-wall diamino acid, and whole-cell hydrolysates contained mainly ribose, xylose, and mannose. The predominant menaquinones of strain TRM S81-3 $3^{\top}$ were MK-9 $\left(\mathrm{H}_{4}\right)$, MK-9 $\left(\mathrm{H}_{6}\right)$, and MK-9 $\left(\mathrm{H}_{10}\right)$. The major cellular fatty acids were iso- $\mathrm{C}_{16: 0}$ (42.06\%), anteiso- $\mathrm{C}_{15: 0}(11.90 \%)$, anteiso- $\mathrm{C}_{17: 1} \omega 9 c(9.19 \%)$, anteiso- $\mathrm{C}_{17: 0}(7.21 \%)$, iso- $\mathrm{C}_{15: 0}(6.94 \%)$ and $\mathrm{C}_{14: 0}(5.93 \%)$. Polar lipids consisted of diphosphatidylglycerol (DPG), phosphatidyl choline (PC), phosphatidyl ethanolamine (PE), phosphatidyl methyl ethanolamine (PME), one phospholipid of unknown structure containing glucosamine (NPG), and two unidentified phospholipids (PLs, Online Resource 1).

Phylogenetic analysis based on $16 \mathrm{~S}$ rRNA gene sequences revealed that strain TRM S81- $3^{\top}$ falls within the genus Streptomyces and had the highest sequence similarity (98.96\%) to Streptomyces naganishii 
NBRC $12892^{\top}$ (GenBank accession no. AB184224). The analysis placed TRM S81-3 ${ }^{\top}$ in a clade with $S$. naganishii NBRC $12892^{\top}$, and its neighbors were two other Streptomyces strains, S. ruber NBRC $14600^{\top}$ and S. roseiscleroticus NBRC $13002^{\top}$. All four species sit on the same branch, and TRM S81-3 ${ }^{\top}$ shares 16S rRNA similarities of $98.37 \%$ and $98.27 \%$ with S. ruber NBRC $14600^{\top}$ and S. roseiscleroticus NBRC $13002^{\top}$, respectively. The phylogenetic analysis also showed that strain TRM S81-3 ${ }^{\top}$ forms a distinct clade from other closely related species of the genus Streptomyces (Fig. 2). The topologies of phylogenetic trees built using the maximum-likelihood (Online Resource 2) and maximum-parsimony (Online Resource 3) algorithms were similar to that of the neighbor-joining tree. The MLSA phylogenetic analysis shows the near neighbor of TRM S81-3 ${ }^{\top}$ is $S$. viridiviolaceus NBRC $13359^{\top}$ (MLSA distance $=$ 0.0206) (Fig. 3), while the MLSA distances were much greater than the generally accepted threshold (> 0.007) for species delineation using this scheme (Rong and Huang 2012). The topologies of phylogenetic trees built using the maximum-likelihood (Online Resource 4) and maximum-parsimony (Online Resource 5) algorithms were similar to that of the neighbor-joining tree. A draft genome sequence was determined for strain TRM S81-3 ${ }^{\top}$. The draft genome size was 8,820,456 bp and comprised 241 contigs. The GC content was $72.1 \%$. Strain TRM S81-3 ${ }^{\top}$ and S. naganishii NBRC $12892^{\top}$ showed $86.26 \%$ ANI to each other, which is below the threshold of the $95-96 \%$ ANI cut-off widely accepted for delineating prokaryotic species (Richter and Rosselló-Móra 2009). Based on differences in phenotypic characteristics and the chemotaxonomic and phylogenetic data, strain TRM S81-3 ${ }^{\top}$ represents a novel species of the genus Streptomyces, for which the name Streptomyces grisecoloratus is proposed. The type strain is TRM S81$3^{\top}\left(=\right.$ CCTCC AA $2020002^{\top}=$ LMG $\left.31942^{\top}\right)$.

Description of Streptomyces grisecoloratus sp. nov.

Streptomyces grisecoloratus (gri.se.co.lo.ra'tus. N.L. masc. adj. griseus gray; L. masc. past part. coloratus colored; N.L. masc. adj. grisecoloratus gray-colored).

Aerobic, non-motile, Gram-positive actinomycete that forms an extensively branched substrate mycelium and aerial mycelium that differentiate into straight spore chains with spiny-surfaced spores. The $\mathrm{pH}$ and $\mathrm{NaCl}$ tolerance ranges for growth are 5.0-10.0 (optimum, $\mathrm{pH} 7.0$ ) and $0-10 \%(\mathrm{w} / \mathrm{v}$; optimum, $0 \% \mathrm{w} / \mathrm{v}$ ), respectively. The temperature range for growth is between $10^{\circ} \mathrm{C}$ and $50^{\circ} \mathrm{C}$ (optimum, $28^{\circ} \mathrm{C}$ ). Poor growth was observed only on ISP5 and Czapek's agar, and it cannot form aerial hyphae on ISP6 medium. Growth on other media is vigorous. No diffusible pigments or melanin were observed on any of the media tested. Uses all carbon sources tested as nutrients, including D-mannitol, D-glucose, L-arabinose, D-fucose, Dxylose, D-fructose, L-rhamnose, D-galactose, D-lactose, D-raffinose, D-inositol, and D-sucrose. Positive for nitrate reduction, catalase production, lipase production, milk coagulation and peptization, starch hydrolysis, cellulose hydrolysis, and urease production but negative for gelatin hydrolysis, oxidase production, melanin production, and $\mathrm{H}_{2} \mathrm{~S}$ production. The diagnostic phospholipids are $D P G, P E, P C, P I$, PME, NPG, and PL. Cell-wall sugars are ribose, xylose, and mannose, and the major menaquinones were MK-9 $\left(\mathrm{H}_{4}\right), \mathrm{MK}-9\left(\mathrm{H}_{6}\right)$, and MK-9 $\left(\mathrm{H}_{10}\right)$. The major fatty acids are iso- $\mathrm{C}_{16: 0}$, anteiso- $\mathrm{C}_{15: 0}$, anteiso- $\mathrm{C}_{17: 1} \omega 9 c$, anteiso- $\mathrm{C}_{17: 0}$, iso- $\mathrm{C}_{15: 0}$, and $\mathrm{C}_{14: 0}$. The genomic DNA G $+\mathrm{C}$ content of the type strain is $72.1 \%$. 
The type strain TRM S81-3 ${ }^{\top}$ (= CCTCC AA 2020002 ${ }^{\top}=$ LMG 31942 ${ }^{\top}$ ) was isolated from cotton fields in Xinjiang, northwest China. The GenBank/EMBL/DDBJ accession number for the 16S rRNA gene sequence of strain TRM S81-3 ${ }^{\top}$ is MT756021. The TRM S81-3 ${ }^{\top}$ genome sequence was deposited in GenBank (JACVQF000000000).

\section{Declarations}

Author contributions L. Xing and Y.-Y. Xia performed the experiments and wrote the initial draft. Q.-Y. Zhang, Z.-F. Xia, C.-X. Wan, and L.-L. Zhang guided the experimental operations. X.-X. Luo contributed reagents, instrumentation, and financial support for this work.

Funding This work was supported by the Program for Young and Middle-Aged Technology Innovation Leading Talents (Project no. 2019CB030), the National Natural Science Foundation of China (Project no. U1703236), the Innovative Team in the Key Areas of the Corps of Microbial Resources (Project no. 2017CB014), and the National Innovative Project for College Students (Project no. 201810757016).

Conflicts of interest The authors declare that there are no conflicts of interest.

Ethical approval No studies with human participants or animals were performed.

\section{References}

Anderson AS, Wellington EM (2001) The taxonomy of Streptomyces and related genera. Int J Syst Evol Microbiol 51:797-814.

Atlas RM (1993) Handbook of microbiological media. In: Parks LC (editor). Boca Raton: CRC Press.

Ay H, Nouioui I, Del Carmen Montero-Calasanz M, Klenk HP, Isik K et al (2018) Streptomyces sediminis sp. nov., isolated from crater lake sediment. Antonie Van Leeuwenhoek 111:493-500.

Collins MD (1985) 11 analysis of isoprenoid quinones. Methods in Microbiology 18:329-366.

Darriba D, Taboada GL, Doallo R, Posada D (2011) ProtTest 3: fast selection of best-fit models of protein evolution. Bioinformatics 27:1164-1165.

Felsenstein J (1981) Evolutionary trees from DNA sequences: a maximum likelihood approach. J Mol Evo 17:368-376.

Felsenstein J (1992) Estimating effective population size from samples of sequences: a bootstrap Monte Carlo integration method. Genet Res 60:209-220.

Gerhardt P, Murray RGE, Wood WA, Smibert RM, Krieg NR (1994) Methods for general and molecular bacteriology. American Society for Microbiology. 
Gordon RA (1974) Nocardia coeliaca, Nocardia autotrophica, and the Nocardin strain. Int J Syst Bacteriol 24:54-63.

Gouy M, Guindon S, Gascuel O (2010) SeaView version 4: A multiplatform graphical user interface for sequence alignment and phylogenetic tree building. Mol Biol Evol 27:221-224.

Groth I, Schumann P, Rainey FA, Martin K, Schuetze B et al (1997) Demetria terragena gen. nov., sp. nov., a new genus of actinomycetes isolated from compost soil. Int J Syst Bacteriol 47:1129-1133.

Hasegawa T, Takizawa M, Tanida S (1983) A rapid analysis for chemical grouping of aerobic actinomycetes. J Gen Appl Microbiol 29:319-322.

Hu H, Lin HP, Xie Q, Li L, Xie XQ et al (2012) Streptomyces qinglanensis sp. nov., isolated from mangrove sediment. Int J Syst Evol Microbiol 62:596-600.

Kämpfer P, Kroppenstedt RM, Peter Kämpfer RMK (1996) Numerical analysis of fatty acid patterns of coryneform bacteria and related taxa. Can J Microbiol 42:989-1005.

Kim SB, Brown R, Oldfield C, Gilbert SC, lliarionov S et al (2000) Gordonia amicalis sp. nov., a novel dibenzothiophene-desulphurizing actinomycete. Int J Syst Evol Microbiol 50:2031-2036.

Kimura M (1980) A simple method for estimating evolutionary rates of base substitutions through comparative studies of nucleotide sequences. J Mol Evol 16:111-120.

Lazzarini A, Cavaletti L, Toppo G, Marinelli F (2000) Rare genera of actinomycetes as potential producers of new antibiotics. Antonie Van Leeuwenhoek, Review 78(3-4):399-405.

Li LY, Yang ZW, Asem MD, Fang BZ, Salam N et al (2019) Streptomyces desertarenae sp. nov., a novel actinobacterium isolated from a desert sample. Antonie Van Leeuwenhoek 112:367-374.

Manfio GP (1995) Towards minimal standards for the description of Streptomyces species.

McCarthy AJ, Williams ST (1992) Actinomycetes as agents of biodegradation in the environment--a review. Gene 115(1-2):189-192.

Minnikin DE, O'Donnell AG, Goodfellow M, Alderson G, Athalye M et al (1984) An integrated procedure for the extraction of bacterial isoprenoid quinones and polar lipids. J Microbiol Methods 2(233-241):233.

Mount DW (2008) Maximum parsimony method for phylogenetic prediction. CSH Protoc 2008:pdb top32.

Piao C, Ling L, Zhao J, Jin L, Jiang S et al (2018) Streptomyces urticae sp. nov. isolated from rhizosphere soil of Urtica urens L. Antonie Van Leeuwenhoek 111:1835-1843.

Pridham TG, Gottlieb D (1948) The Utilization of Carbon Compounds by Some Actinomycetales as an aid for species determination. J Bacteriol 56:107-114. 
Richter M, Rosselló-Móra R (2009) Shifting the genomic gold standard for the prokaryotic species defnition. Proc Natl Acad Sci USA 106:19126-19131.

Rong X, Huang Y (2012) Taxonomic evaluation of the Streptomyces hygroscopicus clade using multilocus sequence analysis and DNA-DNA hybridization, validating the MLSA scheme for Systematics of the whole genus. Syst Appl Microbiol 35:7-18.

Saeng-In P, Phongsopitanun W, Savarajara A, et al (2018) Streptomyces lichenis sp. nov. isolated from lichen. Int J Syst Evol Microbiol 68(11).

Saitou N, Nei M (1987) The neighbor-joining method: a new method for reconstructing phylogenetic trees. Mol Biol Evol 4:406-425.

Seok-Hwan, Yoon, Sung-Min, et al. A large-scale evaluation of algorithms to calculate average nucleotide identity.[J]. Antonie van Leeuwenhoek, 2017.

Shirling EB, Gottlieb D (1966;) Methods for characterization of Streptomyces species. Int J Syst Bacteriol 16:313-340.

Sudhir K, Glen S, Michael L, Christina K, Koichiro T (2018) MEGA X: Molecular Evolutionary Genetics Analysis across computing platforms. Mol. Biol. Evol 35:1547-1549.

Waksman SA (1967) The actinomyces. A summary of current knowledge. J Actinomycetes a Summary of Current Knowledge.

Waksman SA, Henrici AT () The Nomenclature and Classification of the Actinomycetes. J Bacteriol 1943; 46(4):337-341.

Wang Z, Tian J, Li X, Gan L, He L et al (2018) Streptomyces dioscori sp. nov., a novel endophytic actinobacterium isolated from Bulbil of Dioscorea bulbifera L. Curr Microbiol 75:1384-1390.

Whitman WB (2012) Bergey's Manual of Systematics of Archaea and Bacteria.

Yamaguchi T, Saburi Y (1955) Studies on the anti-trichomonal actinomycetes and their classification. J Gen Appl Microbiol 1:201-235.

Ye L, Zhao S, Li Y, Jiang S, Zhao Y et al (2017) Streptomyceslasiicapitis sp. nov., an actinomycete that produces kanchanamycin, isolated from the head of an ant (Lasius fuliginosus L.). Int J Syst Evol Microbiol 67:1529-1534.

Yokota A, Tamura T, Hasegawa T, Huang LH (1993) Catenuloplanes japonicus gen. nov., sp. nov., nom. rev., a new genus of the order actinomycetales. Int J Syst Bacteriol 43:805-812.

Yoon SH, Ha SM, Lim J, Kwon S, Chun J (2017) A large-scale evaluation of algorithms to calculate average nucleotide identity. Antonie Van Leeuwenhoek 110:1281-1286. 


\section{Tables}

Table 1. Characteristics of strain TRM S81-3 ${ }^{\top}$ compared with its most closely related Streptomyces species.

Strains: 1, TRM S81-3' ${ }^{\top}$; , Streptomyces naganishii NBRC $12892^{\top}$ (Yamaguchi and Saburi 1955); 3 , Streptomyces griseomycini NBRC ${ }^{12778}{ }^{\top}$ (Whitman 2012); 4, Streptomyces griseostramineus NBRC $12781^{\top}$ (Whitman 2012).

+, positive; -, negative; ND, not determined. 


\begin{tabular}{|c|c|c|c|c|}
\hline Characteristics & 1 & 2 & 3 & 4 \\
\hline Spore color & Gray & Brownish-gray & Gray & Gray \\
\hline Spore wall ornamentation & Spiny & Smooth & Hairy & Spiny \\
\hline Spore chain morphology & Straight & Spirales & Spirales & Spirales \\
\hline Growth at $50^{\circ} \mathrm{C}$ & + & ND & ND & ND \\
\hline Growth at $10 \% \mathrm{NaCl}$ & + & - & ND & ND \\
\hline $\mathrm{pH}$ range & $5-10$ & $5-11$ & ND & ND \\
\hline milk coagulation and peptization & + & + & + & + \\
\hline Hydrolysis of starch & + & + & + & + \\
\hline Liquefaction of gelatin & - & + & ND & ND \\
\hline \multicolumn{5}{|l|}{ Carbon source utilization: } \\
\hline D-Mannitol & + & + & + & + \\
\hline D-Glucose & + & + & + & + \\
\hline L-Arabinose & + & + & + & + \\
\hline D-Fucose & + & + & + & + \\
\hline D-Xylose & + & + & + & + \\
\hline D-Fructose & + & + & + & + \\
\hline L-Rhamnose & + & + & + & + \\
\hline D-Galactose & + & + & + & + \\
\hline D-Lactose & + & + & + & + \\
\hline D-Raffinose & + & - & - & + \\
\hline D-Inositol & + & + & + & + \\
\hline D-Sucrose & + & - & - & - \\
\hline
\end{tabular}

\section{Figures}



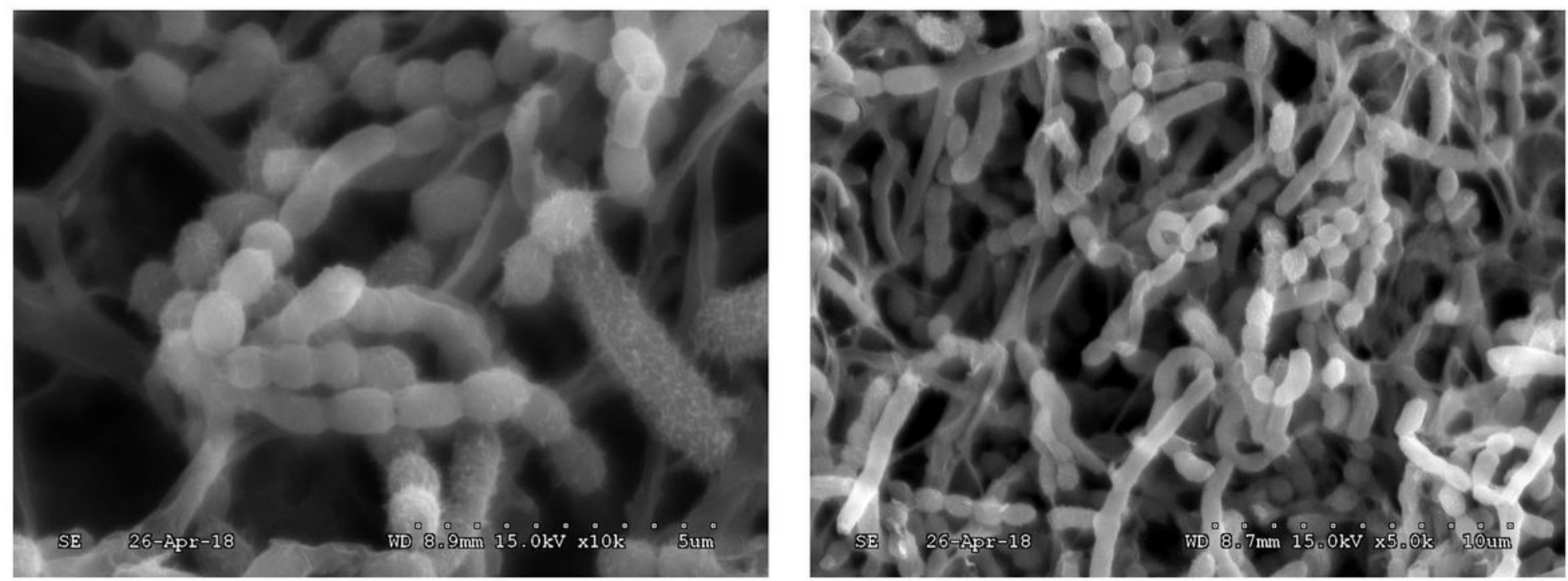

\section{Figure 1}

Scanning electron micrograph of strain TRM S81-3T grown on Gause's medium at $28^{\circ} \mathrm{C}$ for 7 days

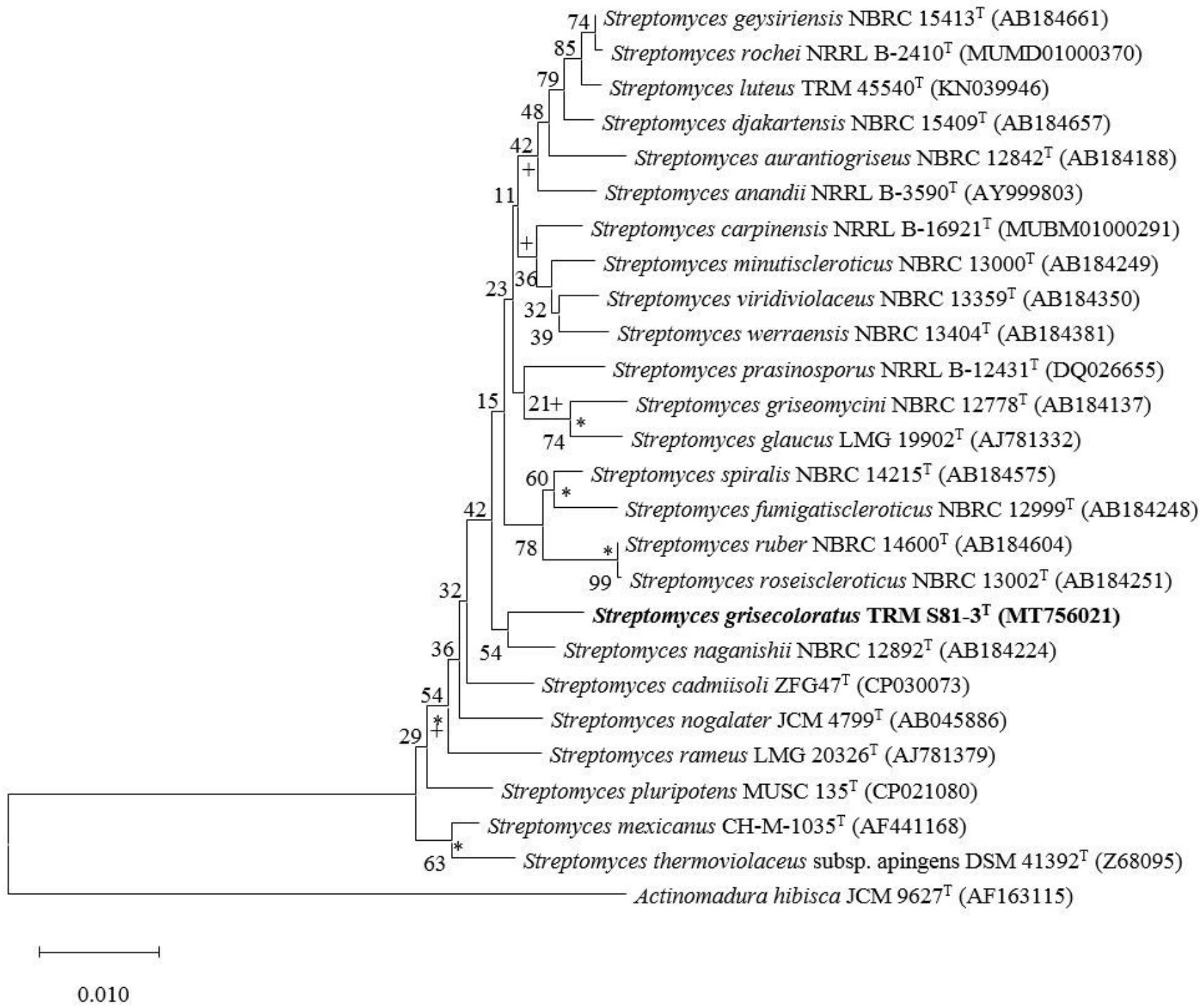




\section{Figure 2}

Neighbor-joining phylogenetic tree based on nearly complete 16S rRNA gene sequences The relationships between strain TRM S81-3T and the type strains of closely related Streptomyces species were analyzed. Actinomadura hibisca JCM 9627T (AF163115) was used as the outgroup. *, branches that were also found using the maximum-parsimony method; + , branches that were also found using maximum likelihood; ${ }^{*}$, branches that were found using all three methods. Numbers at the nodes are percentage bootstrap values based on 1000 replicates; only values above $50 \%$ are given. Bar, 0.0100 substitutions per nucleotide position.

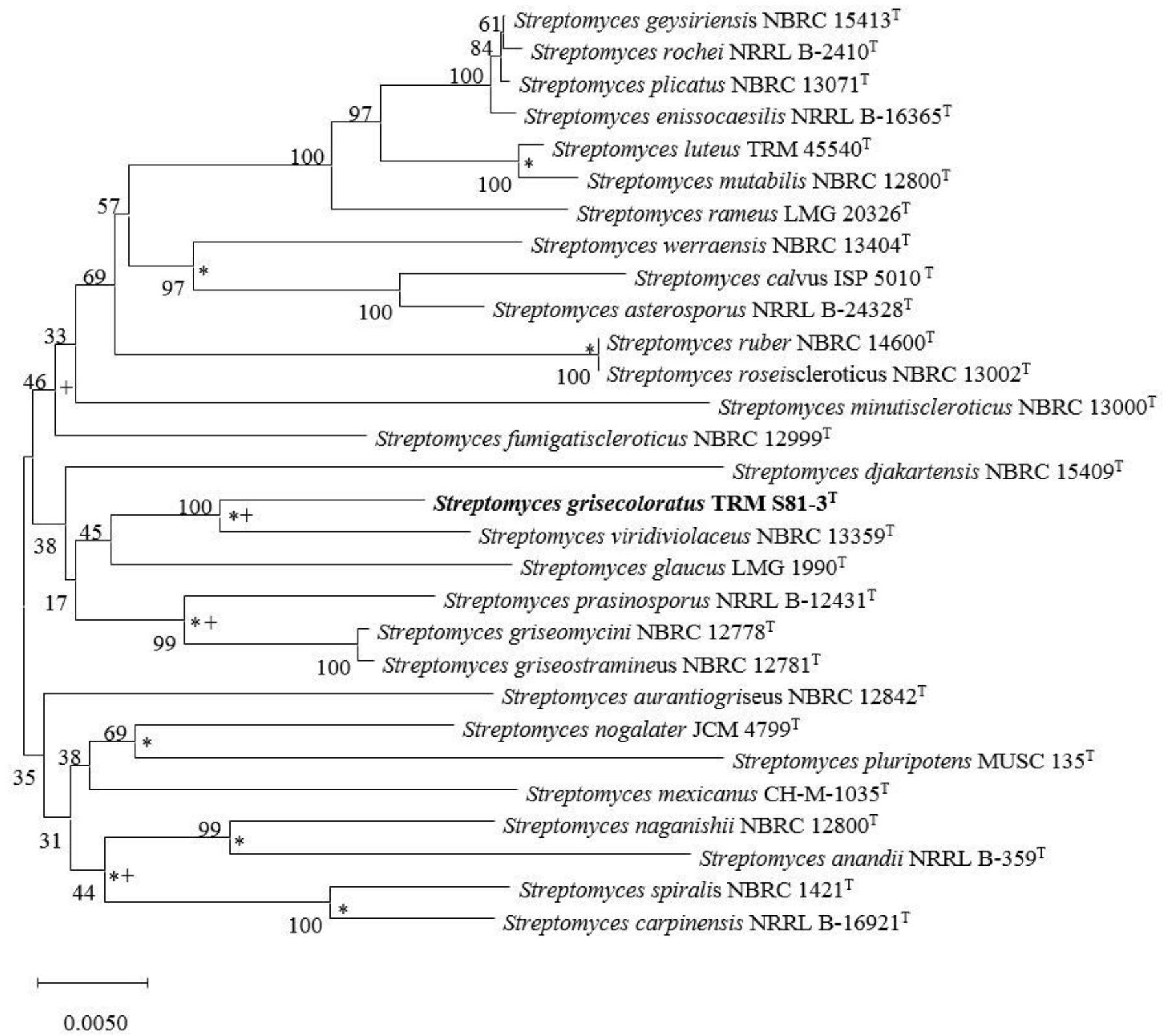

\section{Figure 3}

Neighbor-joining phylogenetic tree based on concatenated partial sequences of the housekeeping genes atpD, gyrB, recA, rpoB, and tyrB The relationships between strain TRM S81-3T and the type strains of closely related Streptomyces were analyzed. *, branches that were also found using the maximum- 
parsimony method; + , branches that were also found using maximum likelihood; ${ }^{*}+$, branches that were found using all three methods. Numbers at the nodes are percentage bootstrap values based on 1000 replicates; only values above $50 \%$ are given. Bar, 0.0050 substitutions per nucleotide position.

\section{Supplementary Files}

This is a list of supplementary files associated with this preprint. Click to download.

- sf1.jpg

- sf2.jpg

- sf3.jpg

- sf4.jpg

- sf5.jpg

- CCTCCAA2020002.pdf

- LMG31942.pdf 